\section{ACCIDENTAL EXPLOSIONS *}

II.

THERE is no doubt whatever that a very considerable proportion of the accidents which occur to persons using petroleum lamps are really traceable to the erroneous belief, which is still so very prevalent, in the explosize character of these liquids. The fact that they and their vapours are simply inflammable, and that the latter requires to be mixed with a large volume of air before their ignition can be accompanied by explosive effects, is so slowly realised, that in public prints petroleum is still often spoken of as an explosive substance. The popular belief in the explosiveness of these simply inflammable liquids contrasts strangely $x$ ith the fact that many explosions have been brought about by the careless employment of candles or other naked flames in premises where the volatile varieties have been stored, or where the operation of transferring the liquid from one vessel to another for purposes of sale is carried on, the result being the ignition of the explosive mixture produced by the volatilisation of the spirit and its diffusion through the air. This fact does indeed tend to discourage the hope that the proportion of accidental explosions of gunpowder which are apparently due to ignorance may become very greatly diminished by keeping its explosive properties before the minds of those using it.

The lecturer then referred to the legislative restrictions in connection with the transfer, storage, and sale of petroleum and petroleum oils. The danger arising more especially from the transport and storage of imperfectly refined oils under designations which apply to the properly refined and therefore safe petroleum- or coal-oils, which do not demand special precautions for their safe storage and use, and are consequently not subject to any restrictive or precautionary regulations, renders the application of the existing Jegal regulations to the inspection of petroleum-oils imported into England of special importance. Referring to the so-called flashingtest described in the Act of Parliament, Prof. Abel thinks it undoubtedly desirable, in the framing of any future Act, that this test should be carefully reconsidered, as well as the question whether some narrow limit below $100^{\circ} \mathrm{F}$. may not reasonably, and without incurring any increased risk, be fixed within which the flashing point of an oil (i.e. the temperature at which it evolves vapour) may range. $t$

The liability of oil or spirit to leak from casks or barrels even of the best construction, consequent upon the rough usage to which these are unavoidably subjected when transferred from store to ship or carriage, and the reverse, need scarcely be pointed out. But even in the absence of leakage from the openings of the barrels, or from any accidental point of escape, evaporation or diffusion of the volatile petroleum will occur through the wood itself of which they are constructed, especially in the warm holds of ships or in stores exposed to the sun, even though the precautionary measure is irequently adopted of rinsing the barrel out before use with a solution of glue. It is evident that the object of im. parting an impervious coating to the interior of the barrel can thus be only very imperfectly attained, and that, even if it were, the alternations of temperature to which the barrels must be exposed must in course of time open up places for escape by leakage or evaporation.

The dangers resulting from the escape of petroleum spirit or its vapour from receptacles in which it is kept, in confined spaces, where little or no ventilation exists, has been but too frequently exemplified by explosions more or less violent, followed by fires in localities where it is stored or handled, or in the holds of vessels in which it is transported. Accidents of such kinds have been due either to carelessness in transferring petroleum from one vessel to another, in a shop or store in which a light has been burning at the time, or to a light being carried into or a match struck in a store where vapour has been escaping until it has formed an explosive mixture with the air. The lecturer had a vivid recollection of an accident of this kind which he witnessed at the Royal College of Chemistry in 1847 . Mr. C. B. Mansfield, who was then engaged in his important researches on the composition of coal-tar naphtha, which led a few years afterwards to his sad untimely death, was engaged at one extremity of a low

* Abstract of a lecture delivered at the Royal Institution, March 12, by Prof. F. A. Abel, F.R.S. Continued from p. 439.

$\dagger$ As the law at present stands, an oil, the flashing-point of which is declared to be $99^{\circ}$ by the official inspector, must be condemned; but another operator may make the flashing.point of the same oil to be slightly above $100^{\circ}$. Practically, an oil with a flashing-point of $97^{\circ}$ or $98^{\circ}$ would be quite as safe as one which inswers to the test at $100^{\circ}$, in the hands of the same operator room ( 38 feet long, about 30 feet wide, and ro feet high) in converrting one of the most important of these products-benzol-(which boils at $176^{\circ} \mathrm{F}$.) into nitrobenzol in a capacious retort, which suddenly cracked, and, yielding to the pressure of its contents, allowed the warm liquid hydro-carbon to flow over the operating table. There was a gas-flame burning at the other extremity of the laboratory, and no other source of fire. Within a very few minutes after the fracture of the vessel a sheet of flume flashed from the gas-flame along the upper part of the room and communicated to the table upon which the liquid had been spilled.

A mong other " accidents" referred to as arising from a similar cause, was the recent explosion of the powder-laden barge in the Regent's Canal. It was established by a sound chain of circumstantial evidence that this explosion must have been caused by the ignition, in the cabin of the barge, of an explosive mixture of air and of the vapour of petroleum, derived from the leakage of certain packages of the spirit which were packed along with the powder.

It is impossible to protect heavy packages from rough usage, in the processes of unloading ships or other vehicles of conveyance ; it is therefore most important that means should be adopted of thoroughly closing the vents of receptacles of petroleum-spirit by such means as are capable of sustaining ordinary rough usage without any injury to their efficiency, and that the improvensent of the nature and construction of the receptacles themselves be seriously considered with the view of reducing the liability to accidents resulting from the escape of the spirit or its vapours, and the consequent creation of danger connected with the transport and storage of these valuable illuminating materials.

The fact that combustible, and especially inflammable, solid substances, if of sufficiently low specific gravity, and reduced to a sufficiently fine state of division to allow of their becoming and remaining for a time suspended in air, may furnish mixtures with the latter which partake of explosive character, scarcely needs to be pointed out. The ignition of a particle of such a substance, surrounded by atmospheric oxygen, will, under these conditions, at once communicate to others immediately adjacent to it, and if the particles of suspended solid matter be sufficiently numerous and finely divided, the ignition will spread throughout the mixture with a rapidity approaching that of a mixture of inflammable vapour and air, the development of gaseous products and heat being sufficiently rapid and considerable to produce explosive effects, which may even be of violent character, their violence being regulated by the nature and inflammability of the solid substance, the proportion and state of division in which it is distributed through the air, the quantity of the mixture, and the extent of its confinement.

Explosions of an accidental nature produced in this way are believed to have occurred in connection with operations in the chemical laboratory; but it was scarcely to be expected that the first clearly authenticated cases of any importance should have axisen out of the apparently harmless operation of grinding corn.

That a mixture of very fine flour and air will ignite with a flash when light is applied to it, and produce in a very mild form the species of explosion observed on applying a light to licopodium suspended in air, is not very difficult of demonstration, but it is not easy to realise the possibility of the production of violent explosive effects by the ignition of such a mixture even upon a very large scale, though the rapidity of its ignition be accidentally favoured by the warmth of the atmosphere. Cotton mills have been known to be rapidly fired by the ignition of cotton particles suspended in the air; but, compared with flour, cotton is very combustible. Flour when absolutely dry would contain only about half its weight of carbon, and about six per cent. of hydrogen, the remainder consisting of nitrogen and mineral substances; constituents which, by absorbing heat instead of contributing to its development, must tend to reduce the rapid combustibility of the substance. Yet the possibility of very serious calamities arising out of the accidental ignition of a mixture of flour-dust and air has been but too conclusively demonstrated.

Referring to a destructive explosion in some extensive steam flour-mills in Glasgow in July 1872, the lecturer said that its origin was conclusively traced to the striking of fire by a pair of millstones, through the stopping of the "feed," or supply of grain to them, and the consequent friction of their bare surfaces against each other, the result being the ignition of the mixture of air and fine flour-dust surrounding the mill-stones.

This ignition alone would not suffice to develop any violent 
explosive effects; such ignitions, though occasionally observed in small mills, being caused either by the striking of fire by the stones, or by the incautious application of a light near the millstones, or the meal-spout attached thereto, have not in these instances been attended by any serious results. But in an extensive mill, where many pairs of stones may be at work at one time, each pair has a conduit attached to it, which leads to a common receptacle called an exhaust-box; into this the mixture of air and very fine flour-dust which surrounds the millstones is drawn by means of an exhaust-fan, sometimes aided by a system of air-blowers. The fine flour is allowed to deposit partially in this chamber or exhaust-box, and the air then passes into a second chamber called a stive room, where a further quantity of dust is deposited. It follows that when the mill is at work these chambers and the channels or spouts connecting them with the atmosphere immediately surrounding each millstone, are all filled with an inflammable mixture of the finest flour-dust and air, and that consequently the application of a light to any one of those channels, or the striking of fire by any one of the millstones, by igniting some portion of the inflammable mixture, will result in the exceedingly rapid spread of flame throughout the confined spaces which are charged with it, and will thus develop an explosion. The violence of such explosions depends much upon details of construction of the exhaust-boxes and stive rooms, and upon the dimensions of the channels of communication ; it must obviously be regulated by the volume of inflammable mixture through which fire rapidly spreads and upon the extent of its confinement.

The subject of flour-mill explosions, though it has attracted little if any attention in this country previous to the Tradeston explosion, is discussed in continental treatises on flour-mills, and the results of Professors Rankine and Macadam's inquiries have demonstrated that accidents of this kind are actually of ordinary occurrence in mills, especially since the introduction of the exhaust arrangements. Those gentlemen point out that it appears scarcely possible to guard against such accidents altogether, although the frequency of their occurrence may probably be much reduced by adopting efficient precautions to prevent, as far as possible, a stoppage of the "feed" to the millstone, or the accidental introduction of nails between them together with the grain, and by prohibiting the employment of naked lights in the vicinity of the mills and the dust passages. In order to reduce as far as possible the damage and risk of sacrifice of life resulting from such explosions, it is important that all receptacles into which the dust-laden air is drawn from the mills should be fixed outside the buildings, and constructed so as to offer as little resistance as possible to the sudden expansion resulting from the ignition of the inflammable mixture. The conduits leading from the mills to the exhaust chambers should, moreover, be of small dimensions, and there should be no other communication between the interior of the building and the dust receptacles, which must not be opened while the mill is at work. By adopting precautions of this kind the mill-owner may succeed, at any rate, in reducing the mischief resulting from an accidental ignition of flour-dust at the millstones to such limits that the mill itself and the lives of those engaged in it will not be endangered.

The production of explosions by mixtures of air with marsh gas, coal gas, petroleum vapours, or a finely divided inflammable solid such as flour, has been slown to be due to the application of sufficient heat to some portion of the mixture to cause the atmospheric oxygen to combine with the combustible constituents of the gas, vapour or solid, the results being the development of chemical action, the formation of gaseous products, and their expansion by the heat developed. It need scarcely be said that the same explanation applies to the producton of explosions by that class of so-called explosive agents which is prepared by intimately mixing combustible or inflammable solids with a solid oxidising agent (i.e., an oxygen compound which readily yields up a part or the whole of that gas under the influence of heat, and with the co-operation of chemical force, to carbon, hydrogen, or other readily oxidisable elements). Distinct from these explosive mixtures as regards their nature, but quite analogous to them in their behaviour and the effects they produce when subjected to heat or other disturbing influences, are explosive compounds. The majority of these contain carbon, hydrogen, and oxygen as the most important components; they are more or less susceptible of sudden or extremely rapid transformation into gases or vapours, attended by development of great heat, in consequence either of their resolution into their elementary constituents, or generally of the rearrangement of these into comparatively simple forms of combination. Some of these explosive compounds are of such unstable character that they are liable to undergo change from very slight inciting causes, such as the existence in them of minute quantities of foreign substances of active chemical character; or they may even be prone to abso. lutely spontaneous charge. In such substances decomposition may be in the first instance established only to a very minute extent, but this decomposition, by the products to which it gives rise, and by the attendant development of heat, however small, may speedily promote further and more rapid change in the mass of the substance, so that eventually decomposition of violent nature may be established, and the principal portion of the compound may suddenly undergo the same transformation into gases or vapours, attended by the same development of heat, as though any one of the agencies (i.e., fire, friction, or percussion) ordinarily employed to determine the explosion of these bodies had been applied. Cases of so-called spontaneous explosion thus brought about are more familiar to scientific and manufacturing chemists than to the general public, but accidental explosions of very alarming, and, in a few instances, of very calamitous character, are on record which, though not actually of spontaneous nature, in the strict application of the term, have been brought about without any apparent application of external inciting agencies, and have hence, from a practical point of view, not been incorrectly classed as spontaneous explosions.

\section{( $T \circ$ be continued.)}

\section{SOCIETIES AND ACADEMIES LONDON}

Mathematical Society, April 8.-Prof. H. J. S. Smith, F.R.S., president, in the chair.-Mr. G. H. Darwin gave an account of two applications of Peaucellier's cells, first, to "the mechanical description of equipotential lines" ; and secondly, to " a mechanical method of making a force which varies inversely as the square of the distance from a fixed point." In this latter case, let $o$ be the fixed pivot of a cell, and suppose the cell to be in equilibrium under the action of two faces, $P$ and $P^{\prime}$, acting at $D$ and $B$. Then by the principle of virtual velocities-

$P^{\prime} . \delta . \circ D+P . \delta . \circ B=0$. Now, $O D . O D=O A^{2}-A D^{2}$

whence

$$
\begin{gathered}
\therefore \frac{\delta \cdot O D}{O D}=-\frac{\delta \cdot o B}{O B} \therefore P^{\prime} . O D=P . O B \\
P=\frac{P^{\prime}\left(O A^{2}-A D^{2}\right)}{o B^{2}}
\end{gathered}
$$

If then $P^{\prime}$ is a constant force acting away from $o, P$ is an attractive force varying as $o b^{-2}$. Mr. Darwin statecl that the idea was the joint production of his brother Horace and himself, and that he entertained the hope that it would be possible to construct a toy to give an ocular proof of elliptic motion. A rough model was exhibited. Sir W. Thomson, F.R.S., expressed his pleasure at having heard the communication, as he had himself failed in trying to get a mechanical means of making such a force. - Sir W. Thomson then made two communications to the Society: one on the integration of the equations for the motions of a system acted on by forces expressed by linear func-

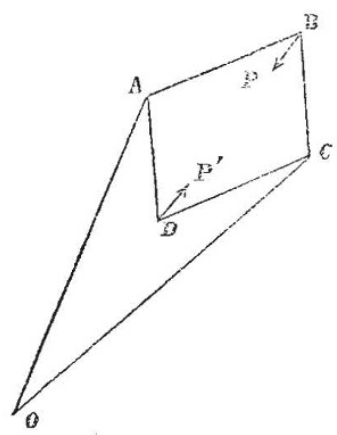
tions of the displacements and velocitics ; the other on the vibra tions of a stretched string of gyrostats (dynamical theory of Faraday's magnetic rotation of the plane of polarisation). Prof. Cayley, F.R.S., made a few remarks on some integrals connected with the theory of attractions.-Mr. Tucker, hon. sec., then read a portion of a paper by Prof. Wolstenholme. The problem discussed in this paper is thus enunciated :-A tube of fine uniform bore is bent into the form of a regular polygon of $n$ sides, and filled with equal volumes of $n$ different fluids which do not mix ; it is then closed, and held in any position in a vertical plane. The sides of the polygon formed by joining the common surfaces of the different fluids will al ways have constant directions; but if two conditions be satisfied, every position will be one of equilibrium. He applies his results to a few simple cases; thus, if $n=3$, and the densities be in arithmetical pro-
gression, the straight line joining the ends of the fluid of 